\title{
Sarah Gensburger (dir.), C'étaient des enfants. Déportation et sauvetage des enfants juifs à Paris / Georges Garel, avec la participation de Katy Hazan, Le Sauvetage des enfants juifs par l'OSE
}

\section{Dina Catenaro-Catenaro}

\section{OpenEdition}

\section{Journals}

Édition électronique

URL : http://journals.openedition.org/temoigner/404

DOI : 10.4000/temoigner.404

ISSN : 2506-6390

Éditeur :

Éditions du Centre d'études et de documentation Mémoire d'Auschwitz, Éditions Kimé

Édition imprimée

Date de publication : 1 septembre 2013

Pagination : 117-119

ISBN : 978-2-84174-643-9

ISSN : 2031-4183

\section{Référence électronique}

Dina Catenaro-Catenaro, « Sarah Gensburger (dir.), C'étaient des enfants. Déportation et sauvetage des enfants juifs à Paris / Georges Garel, avec la participation de Katy Hazan, Le Sauvetage des enfants juifs par l'OSE », Témoigner. Entre histoire et mémoire [En ligne], 116 | 2013, mis en ligne le 01 juin 2015, consulté le 23 octobre 2020. URL : http://journals.openedition.org/temoigner/404 ; DOI : https://doi.org/10.4000/temoigner.404 


\section{LIBRAIRIE}

À pas aveugles de par le monde de Leïb Rocheman Compte-rendu par Judith Lindenberg PAGE 102

Du Communisme et des communistes en Belgique. Approches critiques de José Gotovitch Compte-rendu par Michel Enaudeau PAGE 104

Les Images d'archives face à l'histoire. De la conservation à la création de Laurent Veray Compte-rendu par Chrystel Jeandot PAGE 106

Terres de sang.

L'Europe entre Hitler et Staline

de Timothy Snyder

Compte-rendu par Anne Roche

\section{PAGE 108}

Sauve-toi, la vie t'appelle de Boris Cyrulnik

Compte-rendu

par Corinne Benestroff

PAGE 113
C'étaient des enfants. Déportation et sauvetage des enfants juifs à Paris de Sarah Gensburger

Le sauvetage des enfants juifs par l'OSE de Georges Garel

Compte-rendu par Dina CatenaroCatenaro

PAGE 117

Intellectuels et artistes sous l'occupation. Et la fête continue de Alan Riding Compte-rendu par Anne Roche PAGE 119

Histoire des Justes en France de Patrick Cabanel Compte-rendu par Léon Strauss

PAGE 122

L'Église de France face à la persécution des Juifs, 1940-1944 de Sylvie Bernay Compte-rendu par Gilles Ferragu

PAGE 125 


\title{
À Pas aveugles de par le monde
}

\author{
Leïb Rochman, trad.du yiddish par Rachel Ertel, Paris, Denoël, 2012, 831 p.
}

Par Judith Lindenberg, EHESS

Les secrets de la littérature yiddish sont parmi les mieux gardés. À découvrir le livre de Leib Rochman, et à penser que sans l'entreprise ambitieuse de sa traductrice, Rachel Ertel, on ne l'aurait peut-être jamais eu entre les mains, on ne sait s'il faut se réjouir que la littérature nous offre encore de telles surprises ou s'effrayer de tout ce qu'on ignore. Tout à coup, le fait qu'il soit arrivé jusqu’à nous, alors qu'il aurait pu rester non lu, apparaît comme un miracle. Le livre de Leib Rochman est important à plusieurs égards : d'abord parce qu'il nous fait découvrir un grand écrivain, dont rien n’avait encore été traduit en français auparavant, mais surtout parce qu'il réussit à transmettre une expérience peu racontée, celle de l'existence du survivant du génocide au lendemain de la guerre, dans cette période transitionnelle floue alors que le monde n’a pas encore repris ses marques. Et important, enfin, parce que sa langue d'écriture est le yiddish, et devient elle-même l'un des thèmes du livre, inséparable de son personnage et de son histoire.

Le premier chapitre, intitulé « Le revenant», raconte le retour du personnage, S., dans le ghetto où il a passé une partie de la guerre. Il erre, « à pas aveugles », dans les ruines, espérant tomber sur des visages connus, retrouver les lieux du passé : mais le regard des autres lui renvoie l'image d'un fantôme indésirable. Au tout début, il rencontre une ancienne connaissance, qui s'effraie à sa vue, et il devine qu'elle est enceinte, réalisant qu'« il avait oublié qu'on pouvait encore donner naissance à des enfants ${ }^{1}$.» Il se sent « émasculé, impuissant ${ }^{2}$. À partir de là, les thèmes de la fécondation et de l'engendrement vont devenir centraux dans le livre. Dans le chapitre suivant, « le rabbin appelait ses fidèles à se multiplier et à croître (...) Ce sont les âmes des nouvelles générations qui doivent renaître, car elles n'ont plus ni père ni mère ${ }^{3}$.»

L'engendrement, ici, est d'abord celui du flot de l'écriture qui, en même temps qu'elle transporte son personnage à l'identité fluctuante (tour à tour «S. » ou « je ») à travers l'Europe, charrie tous les grands thèmes de la littérature mitteleuropéenne. Dans ce livre fleuve, chaque chapitre pourrait presque constituer un récit à part. Tout en créant une langue nouvelle, dans un yiddish d'après la catastrophe, Rochman refonde des pans de cette littérature : ainsi «Leysin - le mont des prodiges », chapitre fleuve d'une cent cinquantaine de pages, est une réécriture de La Montagne magique, replacée après l'Anéantissement, et dans laquelle une frange de l'humanité, à part, tente de continuer à vivre. Il y a aussi beaucoup de Kafka dans le récit, à commencer

(1) Leïb Rochman, À Pas aveugles de par le monde, trad. du yiddish par Rachel Ertel, Paris, Denoël, 2012, p. 19.

(2) Ibid.

(3) Ibid., p. 228. 
par ce personnage initial, S., silhouette spectrale errant dans un monde désert. Le quatrième chapitre, intitulé « Le procès d'Amsterdam », reprend l'un des principaux thèmes kafkaïens : le personnage, S., est accusé de « perturber la marche du monde (...) il va de ville en ville, la tête baissée, et son silence obstiné obscurcit le monde ${ }^{4}$. » En cet immédiat après-guerre, la victime est le coupable. Sa culture aussi est appelée à la barre; dans le chapitre suivant se tient «l'Assemblée des livres rescapés, pour décider de leur sort ${ }^{5}$. » Dans la description des livres abandonnés, des « pages orphelines ${ }^{6}{ }$, Rochman adopte un rythme proche du verset. Il inclut son propre livre dans son énumération : « Mon livre à moi veut aussi entrer dans l'inventaire, ne pas en être exclu. Mais il sait qu'il est parmi les derniers ; il est encore à naître, créé après tout ce qui est advenu. Il n’a pas de couverture rigide. Il s'est dissimulé dans un coin, entre les pages déchirées et profanées. Surtout, ne pas être $\mathrm{vu}^{7}$ ! Cette auto-inclusion dénote la très grande lucidité de l'auteur par rapport au sort de la culture juive, et yiddish en particulier, et à la place qu'y occupe son ouvre. La reprise de l'image de la naissance dans ce contexte lie la destinée des hommes à celle de leur culture. Rochman a conscience qu'en écrivant en yiddish, il condamne son ouvre à la nonpostérité; mais le choix s’impose en tant que ce récit découle de toute la culture qui lui a précédée, tout en écrivant après l'Anéantissement et dans la conscience de son irréversibilité : « son numéro des Plaines (...) est inscrit profondément, comme les lettres gravées sur les tables de pierre ${ }^{8}$.» Cette position d'inscription volontaire dans une disparition est sans doute unique.

Dans sa magnifique préface, qui mériterait d'être citée toute entière tant elle arrive à ressaisir en peu de mots un climat, celui des années cinquante, et un moment charnière, celui que vivait la communauté yiddish à cette période, l'écrivain Aron Appelfeld, qui fut le disciple et l'ami de Rochman à Jérusalem dans sa jeunesse, dit de celui-ci qu'« i létait un des derniers en qui la culture juive s'incarnait organiquement ${ }^{9}$.» Né à Minsk-Mazowieska dans un milieu hassidique en 1918, Rochman a baigné dans la tradition religieuse. Il passa la guerre, dans un ghetto, puis dans un camp de travail, et enfin caché; après-guerre, il fut victime du pogrom de Kielce. À Pas aveugles de par le monde a été publié en yiddish en 1968, date de la dernière grande vague antisémite en Pologne, période aussi d'amorce du déclin de la langue et de la littérature yiddish, à travers l'éclatement diasporique de sa communauté. Ainsi, l'écrivain sait qu'il ne s’adresse plus tant à celle-ci quà ceux qui ne sont plus : « son livre à lui était écrit pour les morts et leur parlait des vivants, des rescapés ${ }^{10}$. » C'est sans doute cette écriture « pour les morts », ce récit onirique et halluciné dans un contexte historique précis,

\footnotetext{
(4) Ibid., p. 325.

(5) Ibid., p. 372.

(6) Ibid.

(7) Ibid., p. 376.

(8) Ibid., p. 540.

(9) Ibid., p. 540.

(10) Ibid., p. 735.
} 


\title{
LIBRAIRIE
}

qui en fait à la fois un document exceptionnel sur l'après-guerre en Pologne, plus éclairant pour l'historien que d'innombrables archives, et un chef d'œuvre littéraire, touchant l'universel à partir d'une langue enfouie.

\section{Du Communisme et des communistes en Belgique. Approches critiques}

\author{
José Gotovitch, Bruxelles, Aden, 2012, 433 p.
}

Par Michel Enaudeau, journaliste

Commençons par un aveu : un lecteur français même intéressé par les mouvements ouvrier et communiste européens est plutôt ignorant des affaires du Parti communiste belge (PCB) tant le communisme en Europe a été dominé par la vie des partis allemand, français, italien et espagnol, ce dernier luttant de nombreuses années dans la clandestinité contre la dictature franquiste. C'est pourquoi le livre de José Gotovitch universitaire belge, historien des mouvements de résistance, du mouvement ouvrier en terre belge mérite l'attention.

En entreprenant ce travail, l'auteur a bien conscience de combler le vide historiographique dont pâtit la connaissance du communisme en Belgique. Le constat est lourd : la plupart des études est le fait de travaux d'étudiants, car le communisme intéresse peu les historiens institutionnels. De plus, la pratique historienne marxiste manque. D’ailleurs, José Gotovitch est-il marxiste ? La question est permise au motif du sous-titre de son livre, «Approches critiques ». Sans se reporter au titre de quelques ouvrages de Marx où figure le mot, Gotovitch n'entend pas critique au sens de retournement ou de renversement d'un fondement de la réalité. « Critique » s'entend en un sens plus courant, celui de « esprit critique », examen des sources, souci de la preuve et de l'argumentation tel que le rationalisme du XVIII, l'a mis en œuvre et transmis. Les articles, contributions, conférences ou interventions dans des colloques telle est l'origine, indiquée en bas de page, de ce dense ensemble de textes procèdent de cet esprit dix huitièmiste. Quatre thèmes organisent les quatre parties du livre: « Synthèses », rapports avec l'Internationale communiste et les « partis frères »; « Le PCB acteur politique, social et culturel »; « Guerre, clandestinité, résistance »; enfin, « Parcours militants ».

Fondé en 1921, le parti communiste belge s'étiole en 1989, année de la chute du Mur de Berlin. À partir de 1935, la lutte antifasciste lui confère tout son prestige. Au sortir de la Seconde Guerre mondiale, il compte 87000 adhérents. Mais ce pic est de brève durée : ils ne sont plus que 24000 en 1950. On est tenté de dire aujourd'hui que les raisons de ce déclin sont assez ordinaires, même si l'auteur ne le dit pas ainsi : rôle des dissensions internes ; rapports difficiles avec le mouvement ouvrier et syndical 
belges, en particulier lorsque les conflits sociaux sont vigoureux dans le Borinage et les mines. La violence de classe s'exerce à nu contre les ouvriers, les mineurs comptant souvent leurs morts sans que pour autant parvienne à sétablir un durable et solide lien entre l'initiative sociale et le PCB. Outre le manque de moyens financiers et matériels, l'historien met en avant l'incompétence des cadres, les rapports compliqués et brutaux avec l'Internationale communiste et le Komintern, au point qu'il se demande: de quel parti est-on l'adhérent en 1936 ? Un lecteur peu au fait de l'histoire du Parti communiste français sera étonné d’apprendre que le PCB a été mis, sinon sous tutelle, du moins sous la surveillance idéologique du PCF. Un dirigeant connu, Étienne Fajon, en fut chargé. Un des membres les plus illustres du PCF, Jacques Duclos, réservait à la presse du Parti ses attaques les plus violentes contre les communistes belges. (Gotovitch, sauf erreur, n'indique pas si ces faits sont rapportés par les historiens français du PCF tels Jacques Fauvet, Pierre Juquin, Philippe Robrieux, Marc Lazar, ou d'autres). Surveillance idéologique donc, car le congrès de 1954 du PCB, dénonce les dérives sectaires du parti entre 1945 et 1954 (période qui correspond à l'impressionnante chute du nombre d'adhérents). Sans parler de l'inévitable soupçon de trotskisme. Du point de vue de la vie politique belge, la fracture importante sera la rupture avec la sociale-démocratie. Le motif est de taille : la reconnaissance par le gouvernement belge du régime du général Franco.

José Gorovitch apporte infatigablement une masse de détails et de précisions qui sont tour à tour d'ordre démographique, social, géographique, économique, donnant ainsi une description en quelque sorte très intime de ce communisme et des communistes belges, grands ou petits, pendant ou après la guerre. Mais cette minutieuse investigation peine à faire émerger une problématique politique d'envergure à laquelle relier l'ensemble de ces sortes d'études monographiques. On regrette quelques propos qui tranchent vivement avec le sérieux et l'ampleur de l'information, tel celui-ci (p. 83): «Fille â̂née de l'Église communiste en Europe occidentale, le PCF...) Comment reprendre, sans guillemets, cette vulgate commune (le communisme est une Église), ce faux et faible discrédit du communisme, quand on consacre autant de temps et de pages à en rendre compte ? De même, José Gotovitch écrit : «précurseur d'un Amnesty International de gauche... » Y aurait-il deux Amnesty International, un de gauche, un de droite?

D'où l'historien tient-il cela ? Nous ne le savons pas. 


\title{
Les Images d'archives face à l'histoire. De la conservation à la création
}

\author{
Laurent Veray, Chasseneuil-du-Poitou, CNDP (Coll. Patrimoine références), 2011, 319 p.
}

Par Chrystel Jeandot, Université Paris 3 Sorbonne-Nouvelle

Laurent Veray, professeur d'études cinématographiques et audiovisuelles à l'Université Paris 3 Sorbonne-Nouvelle, propose une réflexion magnifiquement illustrée sur un objet d'étude qui lui est cher : les « images d'archives ». Il s'agit ici de questionner l'usage de ces documents, de « mieux comprendre la problématique du réemploi des images dans une perspective historique ou mémorielle. » Ces images sont des « identifiants du passé supposés fiables », mais elles agissent également comme stimulation pour la création cinématographique et artistique. Enfin, elles ont une valeur pédagogique. Ainsi, les images d'archives constituent un matériau riche, multiple et propice au réemploi.

Comme le témoignage, les images d'archives portent en elle un paradoxe. Elles évoquent un « temps réel décalé » en étant le « présent d'un passé qu'elles réactualisent. » C'est pourquoi l'auteur évoque, en reprenant les mots de Boleslas Matuszewski, un « processus résurrecteur ». C’est probablement cette caractéristique qui inspire autant de fascination et d'usages différents pour l'image d'archive. Laurent Véray nous rappelle d'ailleurs l'origine de ces premières images et la manière dont elles se sont progressivement répandues, la Première Guerre mondiale représentant un moment-clé en ce qu'elle a été le « premier événement médiatisé ».

Le premier chapitre est d'ailleurs consacré à la genèse des premiers reportages photographiques et cinématographiques qui deviendront, plus tard, les premières archives visuelles et audiovisuelles. En témoigne le retour détaillé de l'auteur sur les Archives de la planète, initiative d'enregistrement cinématographique d'événements, mais également de scènes de la vie quotidienne de l'époque que l'on doit à Albert Kahn dès 1912. C'est également l'occasion d'insister sur un présupposé répandu à l'époque : l'image, en tant que procédé technique (et chimique), évoquerait une vérité et, à ce titre, constituerait une source essentielle pour l'histoire. On pourrait citer les propos révélateurs de Marcel l'Herbier, invoqué par l'auteur : « La caméra, selon moi, fait voir ce que n'ont pas pu voir ceux qui ont vu. »

Le point de vue historique adopté par Laurent Véray met en exergue la complexité de la notion d' « images d'archives » car, ce qui est un jour déclaré « archive», représentait autrefois une "image d'actualité ». " Dès sa création, un document devient donc potentiellement une archive », même si l'auteur précise que ce changement de statut de l'image, ce passage de document à archive, est difficilement identifiable. Dans ce cadre, l'image deviendrait-elle archive lorsque l'historien, le documentariste, ou le chercheur en décide ? Si l'on accepte ce fait, il faudrait peut-être questionner la manière dont l' " image d'archive » est associée par notre auteur au « témoignage 
visuel ». Car, à aucun moment n'est proposée une réflexion sur le rapprochement, peut-être un peu rapide, de ces deux notions.

Quoi qu'il en soit, les images d'archives changent de statut au travers de leur réemploi. Leur sens se trouve modifié à travers le temps et au long de leurs usages et de leurs réinvestissements. C'est d'ailleurs autour de ces réappropriations et réinterprétations que se concentrent les deuxième et troisième chapitres : « film composé », « film de montage », «film de commémoration », l'auteur retrace l'évolution historique de ces différents usages de l'archive. L'exemple d'un reportage allemand de 1917, l'U-35, lui permet de rendre manifeste la façon dont les mêmes images vont pouvoir être réutilisées avec des commentaires bien différents selon le pays dans lequel le film sera montré.

Et c'est bien parce que l'usage de ces documents photographiques et cinématographiques peut venir modifier son sens premier qu'il faut, comme le préconise Laurent Véray, questionner l'image et l'intentionnalité de leur auteur (encore conviendrait-il de rappeler que cela n'est pas toujours possible). Ainsi, et c'est une des conclusions de l'ouvrage, « il y a maintes possibilités de faire de l'histoire avec les images », si l'on n'oublie pas que l'important sera ce que le réemploi « donnera à penser et non seulement à voir. »

La complexité de l'image d'archive est d'ailleurs renforcée par l'attrait contemporain pour l'image quelle qu'elle soit et par la multiplication de documentaires de plus en plus standardisés réemployant des images d'archives très diverses. Il faut dire que, dès 1915, s'est posée la question de la conservation des archives, et le réemploi de ces dernières se fait dès les années 1920 dans les « films rétrospectifs », par exemple. Or, dans ces nouveaux emplois, les images se retrouvent prises dans une narration. Le résultat est une forme hybride évoquée par l'auteur au travers de plusieurs exemples révélateurs tels les trois créations d'Henri Desfontaine en 1917 et 1918 où se mêlent volonté documentaire et trame fictionnelle.

On pourrait ainsi distinguer quatre réemplois principaux de l'image d'archive. Le premier consistant à réutiliser cette dernière dans un film de fiction, car elle viendrait « authentifier la réalité du référent » pour reprendre les propos de Roland Barthes cités par l'auteur. L'usage de l'image d'archive peut également être au service d'usages expérimentaux et artistiques ; l'auteur s'arrête d'ailleurs longuement sur les Histoire(s) du cinéma de Jean-Luc Godard où les images d'archives sont juxtaposées ou confrontées à d'autres formes. « Dès lors, la nature même de ces images change. Elles passent du régime représentatif au régime esthétique. » Les images d'archives sont aussi largement réemployées dans des films documentaires. Une minorité d'entre eux ayant une ambition que l'auteur qualifie de qualitative, proche de celle du chercheur, en adoptant un point de vue sur l'événement et en acceptant la subjectivité de l'image. Néanmoins, le réemploi majoritaire de l'image d'archive concernant le travail documentaire, au grand regret de l'auteur, est celui de l'illustration. À ce titre, les images se retrouvent juxtaposées et parfois combinées, à des scènes de reconstitution, voire à des effets spéciaux. Lauteur émet une vive critique envers certaines de ces productions télévisuelles actuelles, notamment certains « docu-fictions », en plaidant 


\title{
LIBRAIRIE
}

pour une véritable réflexion autour de l'image et des liens qu'elle entretient entre passé et présent. Il rappelle ainsi que montrer n'est pas expliquer et que la marchandisation de l'image est un possible danger qui nous éloigne de leur compréhension.

\section{Terres de sang. L'Europe entre Hitler et Staline}

\author{
Timothy Snyder, traduit de l'anglais par Pierre-Emmanuel Dauzat, \\ Paris, Gallimard, 2012, 705 p.
}

Édition soutenue par une subvention de la Fondation Auschwitz attribuée aux éditions Gallimard

Par Anne Roche, Université Aix-Marseille

Dans l'abondante littérature consacrée à la période de 1933-1945, l'ouvrage de Timothy Snyder est appelé à faire date, par l'ampleur de sa documentation et par l'ambition du projet. Le lecteur intéressé par l'histoire du siècle dernier croit connaître la question, mais Snyder fait plus que compléter le déroulement des faits, il en propose une articulation à la fois neuve et nuancée, aussi éloignée des raccourcis ou des équivalences polémiques qu'engagée dans une perspective humaniste au meilleur sens du terme.

Il s'agit en premier lieu de renouveler les découpages habituels, politiques et géographiques, en focalisant l'étude sur les « terres de sang », celles où vivaient la plupart des Juifs d'Europe et où les plans impériaux de Hitler et de Staline se chevauchèrent : Pologne, pays baltes, Biélorussie soviétique, Ukraine soviétique, frange occidentale de la Russie soviétique.

Les crimes de Staline sont souvent associés à la Russie, et ceux de Hitler à l'Allemagne. Or la partie la plus meurtrière de l'Union soviétique était sa périphérie non russe, et les nazis tuèrent généralement au-delà de l'Allemagne. On situe habituellement l'horreur du XX $\mathrm{X}^{\mathrm{e}}$ siècle dans les camps. Or ce n'est pas dans des camps de concentration que la plupart des victimes du nazisme et du stalinisme trouvèrent la mort. Ces malentendus concernant les sites et les méthodes du meurtre de masse nous empêchent de percevoir l'horreur du siècle.

À partir de ces nouveaux découpages, l'auteur ne propose rien moins que de fonder une nouvelle historiographie. Il suggère en effet, ce qui peut surprendre et même choquer, que notre façon de penser est contaminée par les pouvoirs de l'époque : penser que « les crimes du régime nazi [sont] si grands qu'ils se situent hors de l'histoire », c'est un écho de la croyance hitlérienne du triomphe de la volonté sur les faits. Justifier les crimes de Staline par la nécessité de créer un État moderne, c'est suivre l'idée de Staline que l'histoire ne suit qu'un seul cours. «À moins d'une histoire construite et défendue sur des fondements entièrement différents, nous constaterons 
que Hitler et Staline continuent de définir pour nous leurs propres œuvres. » Cette nouvelle histoire repose sur des principes apparemment simples : postuler qu' « aucun événement du passé n'est au-delà de la compréhension historique ni hors de portée de l'investigation historique », porter une attention rigoureusement chronologique aux meurtres de masse, et admettre que l'être humain a une marge de liberté, comme le montrent les nombreux gestes de résistance ou de simple solidarité humaine au cœur des situations les plus dramatiques.

Il est bien difficile de résumer en quelques pages la richesse de l'ouvrage, nécessaire néanmoins d'en donner une brève idée. Lauteur organise son propos selon un ordre chronologique : partant de la guerre de 1914-1918, qui est à l'origine plus ou moins directe des régimes nazi et soviétique, et allant jusqu'au « complot des blouses blanches » et à la mort de Staline (1953). Le chapitre Famines soviétiques analyse la grande famine de 1933, résultat du premier plan quinquennal, avec la liquidation des koulaks en tant que classe, les déportations vers la Sibérie ou le Kazakhstan, la collectivisation brutale des terres, les réquisitions irréalistes qui obligent les paysans à livrer leurs semences, compromettant ainsi les futures récoltes. Des récits terrifiants font état de cannibalisme, de parents tuant leurs enfants... À l'automne 1933, Roosevelt est alerté par des activistes ukrainiens, alerte sans résultat : en novembre, les USA reconnaissent officiellement l'URSS. (On ne peut que songer, mutatis mutandis, aux démarches de Jan Karski auprès du gouvernement des États-Unis et à leur peu d'effet). Le recensement soviétique de 1937 dénombre 8 millions de personnes de moins que prévu. Réaction de Staline, il fait exécuter les démographes...

Par une sorte d'alternance ironique de l'histoire, le chapitre Terreur de classe occulte en quelque sorte le précédent: «La montée de Hitler au pouvoir en Allemagne éclipsa la seconde révolution de Staline en Union soviétique, la collectivisation et la famine qu'elle provoqua. » Hitler utilise la famine en Ukraine, « la plaçant au cœur d'un débat idéologique avant que sa vérité historique ne soit établie. » Mais à l'inverse, la ligne stalinienne de «classe contre classe » sert Hitler, en interdisant l'union des communistes et des sociaux-démocrates qui, réunis, avaient une base populaire plus large que les nazis. La ligne sera abandonnée en 1934 au profit de l'« antifascisme », mais trop tard pour les gauches allemandes. On pourrait croire que l'antifascisme est une politique d'union et d'ouverture, ce fut - relativement - le cas en France avec le Front populaire, mais en URSS il coïncide avec des purges sanglantes au sein de l'armée, du parti et du NKVD, prélude à la Grande Terreur stalinienne qui, en 19371938, allait coûter la vie à des centaines de milliers de personnes pour des raisons de classe ou de nation. De même la terreur nazie de 1936-1938 cible des groupes sociaux définis pour ce qu'ils étaient (et non ce qu'ils auraient pu faire) : desdits « asociaux » (homosexuels, vagabonds, alcooliques...), les Témoins de Jéhovah. Les nazis créent tout un réseau de camps de concentration, mais la comparaison des chiffres est parlante : fin 1938, le Goulag compte plus d'un million de déportés, et 380000 condamnations à mort ont été prononcées, alors que du côté nazi, les camps comptent environ 20000 personnes, et seulement 267 condamnations à mort.

Après la Terreur de classe, la Terreur nationale. Staline met en place le meurtre de 


\section{LIBRAIRIE}

masse de plusieurs nationalités soviétiques, en premier les Polonais, boucs émissaires des échecs de la collectivisation en Ukraine. Or, l'image de l'URSS était celle d'un État multiculturel et tolérant : « la tuerie ethnique eut l'effet d'un choc » y compris au plan intérieur, car le NKVD est multiculturel et incarne une sorte d'internationalisme. Ici encore, des chiffres qui font réfléchir : 1937, un tiers des officiers supérieurs du NKVD sont juifs. En 1938, ils ne sont plus que $20 \%$, et en 1939, moins de $4 \%$. Après l'Ukraine, la Biélorussie est « épurée » de ses « espions » polonais : « les Polonais représentent un huitième des victimes de la Grande Terreur [...] un pourcentage renversant au regard de l'infime minorité de Polonais qui vivaient en Union soviétique : moins de 0,4\% de la population. » Lépuration polonaise servit de modèle à toute une série d'autres « actions nationales » visant les diasporas de Lettonie, Estonie, Finlande.

Ici l'auteur nous oblige à reconsidérer nos évidences historiques : à l'époque, en Europe occidentale, on ne voit - dans le meilleur des cas - que les grands procès et les purges du parti et de l'armée, mais ces événements furent moins meurtriers que l'action contre les koulaks et contre certaines minorités nationales. De même, toujours en Europe occidentale, on est au courant de l'oppression des Juifs en Allemagne, mais on ignore généralement qu'« à la fin de l'année 1938, l'URSS avait tué près de 1000 fois plus de gens que l'Allemagne nazie pour des raisons ethniques. En fait, les Soviétiques avaient tué à cette date beaucoup plus de Juifs que les nazis. [...] non parce qu'ils étaient Juifs, mais pour la simple raison qu'ils étaient les citoyens du régime le plus meurtrier de l'époque.»

Le chapitre L'Europe de Molotov et de Ribbentrop commence par l'invasion de la Pologne, d'abord par les Allemands, puis par les Soviétiques. La France et la Grande-Bretagne déclarent la guerre à l'Allemagne, mais sans lancer d'action militaire significative, et la Pologne combat seule : l'auteur rappelle la défense héroïque de la poste de Dantzig, épisode immortalisé par Günter Grass dans Le Tambour. Peu après, les Soviétiques à leur tour entrent en Pologne, déportent les officiers, décapitant ainsi la société polonaise. Hitler pensait de même: «seule peut être réduite en esclavage une nation dont on a détruit les couches supérieures. » Or, Hitler avait déjà élargi le Reich avec l'Autriche et la Tchécoslovaquie, mais jamais en intégrant des territoires peuplés d'une aussi forte population non allemande. Paradoxalement, « dans sa croisade pour la pureté raciale, l’Allemagne était devenue fin 1939 le deuxième État multinational d'Europe. Le premier, bien entendu, était l'Union soviétique. »C'est aussi en Pologne que sont exécutés des patients d'hôpitaux psychiatriques (octobre-novembre 1939), procédure qui va être étendue à l'Allemagne : plus de 70000 Allemands seront gazés pour « vie indigne d'être vécue. » Les Soviétiques de leur côté exécutent des officiers prisonniers de guerre polonais, à Katyn. Mais en juin 1941, quand l'Allemagne attaque l'Union soviétique, « d'ennemies, la Pologne et l'Union soviétique se transformèrent soudain en alliées. »

Le chapitre Économie de l'apocalypse marque le début d'une nouvelle période, que l'on peut récapituler comme suit :

- 1933-1938 : l’URSS est responsable des tueries de masse

- 1939-1941 (alliance soviéto-nazie) : « carnage équilibré » 
- 1941-1945 : l'Allemagne est responsable de la quasi-totalité des tueries de masse.

« La collectivisation avait produit la famine en Ukraine. [...] Hitler, en revanche, planifia délibérément de faire mourir de faim des populations soviétiques indésirables. [...] À la fin de 1941, le premier groupe de victimes mortelles du pouvoir allemand en Pologne n’était ni les Polonais ni les Juifs, mais les prisonniers de guerre soviétiques. »

Dans le chapitre Solution finale, l'auteur analyse comment Hitler reformule les buts de guerre : il ne s'agit plus de détruire l'URSS, mais d'exterminer les Juifs. Cette politique va se trouver mise en œuvre notamment dans les pays baltes, d'abord incorporés à l'URSS : dès l'invasion allemande en juin 1941, des pogroms sont organisés, avec l'aide des populations locales, en Lituanie, en Lettonie, en Estonie. «Cette nazification psychique aurait été bien plus difficile sans les preuves tangibles des atrocités soviétiques. » En septembre 1941, c'est le massacre de Babi Yar à Kiev, «premier effort pour assassiner toute la population juive autochtone d'une grande ville. » En octobre 1941, des installations de gazage sont en chantier à Chelmno et à Belzec. Le chapitre Holocauste et vengeance est focalisé sur la Biélorussie, centre de l'affrontement entre Allemagne et URSS. Nombre de Juifs à Minsk, devenus partisans pour résister aux Allemands, soutiennent de fait une politique soviétique qui attirait des représailles sur les civils : « la guerre de partisans en Biélorussie fut un effort perversement interactif de Hitler et de Staline. »

Usines de la mort nazies rappelle la chronologie de la mise en œuvre des camps: Belzec, Sobibor, Treblinka, Auschwitz. Résistance et incinération est consacré à la résistance polonaise et juive, avec une analyse précise des forces en présence, des divergences politiques et stratégiques, et relate le soulèvement du ghetto de Varsovie (avril 1943) puis l'insurrection de Varsovie (1 ${ }^{\text {er }}$ août 1944) et la férocité de la répression. Ici encore, l'auteur renouvelle la perspective : les Américains qui libérèrent BergenBelsen et Buchenwald crurent avoir découvert les horreurs du nazisme, mais comme le savaient les Juifs et les Polonais de Varsovie, et comme le savaient Vassili Grossman et les soldats de l'Armée rouge, ils étaient loin de la vérité. Le pire était dans les ruines de Varsovie, dans les champs de Treblinka, les marais de la Biélorussie ou les fosses de Babi Yar. L’Armée rouge libéra tous ces lieux, et la totalité des terres de sang. Tous les sites du carnage et toutes les villes mortes se retrouvèrent derrière un rideau de fer, dans une Europe que Staline fit sienne tout en la libérant de Hitler.

Dans le chapitre Nettoyages ethniques, on constate que la fin de la guerre n'a nullement été la fin des politiques d'épuration raciale. En janvier 1945, quand l'Armée rouge atteint les restes de Varsovie, Staline a le projet d'une Pologne communiste et ethniquement homogène. C'est ainsi que le gouvernement polonais s'efforce de rendre la vie impossible aux Allemands pour qu'ils partent vers l'Ouest : en Silésie l'allemand est interdit dans les lieux publics, les écoles allemandes fermées, les biens allemands saisis. Lauteur souligne une fois de plus la terrible articulation entre le régime hitlérien et le régime stalinien : «Comme souvent, c'est la politique hitlérienne qui rendit possibles les crimes staliniens. [...] Les nazis avaient négligé d'organiser des évacuations systématiques.» Les exactions contre les civils allemands, évoquées par Günter Grass 


\section{LIBRAIRIE}

dans En crabe, ne sont que trop réelles, mais l'auteur rappelle également que beaucoup plus de citoyens soviétiques et polonais moururent en fuyant les Allemands, que d'Allemands en fuyant les Soviétiques. [...] La fuite, l'évacuation et le travail forcé se soldèrent, directement ou indirectement, par la mort de quelques millions de citoyens soviétiques et polonais. [...] La conduite de maints soldats soviétiques fut certainement tolérée par le haut commandement et espérée par Staline; mais l'Armée rouge n’aurait jamais pénétré en Allemagne si la Wehrmacht n’avait pas envahi l'URSS.

Le chapitre Antisémitisme stalinien commence par l'assassinat de Solomon Mikhoels, directeur du théâtre yiddish de Moscoul, qui avait tenté d'alerter Staline sur le sort des Juifs pendant la guerre, et qui en 1947 intervint auprès de Jdanov pour autoriser la publication du Livre noir sur l'extermination des Juifs, documents et témoignages réunis par Vassili Grossman, Ilia Ehrenbourg et d'autres. Mais «la culture soviétique de lère Jdanov ne pouvait approuver une histoire juive de la guerre », car elle entre en contradiction avec l'histoire de la Grande Guerre patriotique. Soviétiques et Alliés étaient d'accord pour ne pas présenter la guerre comme une guerre de libération des Juifs. En version éclairée : « hésitation de principe à l'idée d'endosser la vision du monde raciste de Hitler. » En version moins éclairée : « concession à l'antisémitisme populaire, très présent en Union soviétique, en Pologne, en Grande-Bretagne et aux États-Unis. » Alors que les dirigeants soviétiques avaient plutôt soutenu l'État d'Israël au moment de sa création, fin 1948-début 1949 se fait un virage antisémite : la Pravda exclut ses collaborateurs juifs, des officiers juifs sont renvoyés de l'armée, des activistes juifs écartés des postes de direction dans le parti. Une centaine d'écrivains et d'activistes juifs sont arrêtés comme «nationalistes juifs» et «cosmopolites déracinés ». En Pologne, les communistes juifs les plus en vue, en raison de l'antisémitisme de Staline (et de l'antisémitisme populaire polonais) en viennent à nier l'importance de l'Holocauste. La mort de Jdanov, qui avait précisément bloqué la publication du Livre noir sur l'extermination des Juifs permet à Staline de lancer l'idée d'un «terrorisme médical juif ». À Prague, Slansky, censé incarner le « nationalisme bourgeois juif » est arrêté et exécuté. La mort de Staline met fin au « complot des blouses blanches ». Mais de toute façon, cet antisémitisme stalinien n’a pas l'efficacité de la « Grande Terreur », et les successeurs de Staline délaissèrent la terreur de masse.

Les grandes lignes de ce résumé ont déjà permis de faire apparaître le bouleversement historiographique proposé par Snyder. Pour le rappeler en une formule de la conclusion, « dans cette concurrence des mémoires, l'Holocauste, les autres politiques allemandes de tuerie en masse et les massacres staliniens devinrent trois histoires différentes, alors même que, dans la réalité historique, ils appartenaient au même espace et à la même époque. » Lauteur se situe par rapport aux analyses d'Arendt sur le totalitarisme et à celles de Vassili Grossman, la différence entre les deux approches étant liée à l'époque à laquelle elles ont été formulées : Arendt écrit à un moment où l'URSS et l'Allemagne nazie sont alliées, Grossman au moment où

(1) L’assassinat de Mikhoels est évoqué dans le roman d’Arkadi Vaïner et Gueorgui Vaïner, La Corde et la pierre, Paris, Gallimard (Coll. Série noire), 2006. 
elles sont en guerre. «Grossman entendait non pas unifier analytiquement les deux systèmes au sein d'une même grille sociologique (comme le totalitarisme d'Arendt), mais les délivrer des explications idéologiques qu'ils donnaient d'eux-mêmes, et ce faisant lever le voile sur leur inhumanité commune.» Et l'auteur enfin prend position sur la « filiation » qui ferait remonter nazisme et stalinisme aux Lumières, comme l'ont suggéré en leur temps Adorno et Horkheimer, en soulignant que « la catastrophe de 1941 [...] est moins liée à l'héritage intellectuel des Lumières et davantage aux possibilités de l'impérialisme.»

Dans les controverses qui ont suivi la parution de Bloodlands, certains historiens anglo-saxons ont critiqué ce qu'ils percevaient comme une équivalence entre le génocide nazi et les meurtres de masse sous Staline. Il nous semble que cette critique n’est pas fondée. Snyder précise : « Seule l'acceptation franche des similitudes entre les systèmes nazi et soviétique permet d'en comprendre les différences » et, à aucun moment, il ne suggère une assimilation totale. Son refus de «l'incompréhensible », sa mise en garde sur l'identification aux victimes, sur les limites des commémorations, son insistance sur le rôle de la mémoire et de l'histoire, font de son livre un outil extrêmement précieux.

\section{Sauve-toi, la vie t'appelle}

\section{Boris Cyrulnik, Paris, Odile Jacob, 2012, 291 p.}

Par Corinne Benestroff, Université Paris 8

Poursuivant le récit instauré en 2008 avec Je me souviens ${ }^{1}$..., Boris Cyrulnik nous livre son histoire. Neuropsychiatre, éthologue, directeur d'enseignement à l'Université de Toulon, on ne présente plus celui dont le nom est désormais associé au concept de résilience dont il fut l'introducteur en France avec le succès que l'on sait.

Né le 26 juillet 1937 à Bordeaux dans une famille de Juifs polonais, Boris Cyrulnik est l'un des 20000 enfants juifs cachés en France pendant la guerre. Son père, engagé dans la Légion est blessé au combat. Arrêté, il est déporté à Auschwitz en 1942. Sa mère, résistante, le place à l'Assistance publique la veille de son arrestation, elle sera déportée à Auschwitz. Tous deux y périront. Le jeune Boris séjourne dans différentes familles d'accueil, un foyer rural, avant d'être recueilli par une institutrice, Marguerite Farges (Margot). Cette dernière le confie à sa mère. Le 10 janvier 1944, Boris est arrêté sur dénonciation. Ce jour-là, il naît une deuxième fois, nous dit-il : « Ma seconde naissance, elle, est en pleine mémoire. Une nuit, j’ai été arrêté par des hommes armés qui entouraient mon lit. Ils venaient me chercher pour me mettre à mort. Mon histoire

(1) Boris Cyrulnik, Je me souviens..., Paris, Odile Jacob (Coll. Poches), 2010. 
est née cette nuit-là. » (p. 11) Transféré à la synagogue où sont rassemblés les Juifs, l'incroyable se produit: le jeune garçon sévade par une fenêtre, dévale l'escalier, plonge avec la complicité d'une infirmière dans une camionnette. Il se retrouve sous un matelas où gît une femme blessée. Il serait dommage de dévoiler toutes les péripéties du parcours de l'auteur qui tresse écriture de l'intime et analyse.

Il y a l'enfant dont l'auteur reconstitue les perceptions, l'escalier de la synagogue paraissait si grand, les émotions, « pourquoi ne me croit-on pas? », les pensées, « que peut donc signifier être juif ? », ce mot énigmatique entendu pour la première fois lors de son arrestation. Il y a aussi l'homme devenu chercheur qui se penche sur cet enfant. Que nous dit-il ? Que la réalité est plurielle, changeante, paradoxale. Ainsi, contre toute attente, une arrestation peut être vécue comme une fête après une période de claustration et d'isolement, un enfant pauvre ne se perçoit pas nécessairement comme tel, un bavard parle pour mieux se taire, la paix peut être plus douloureuse que la guerre ${ }^{2}$.

Il y a l'adulte qui porte un regard distancié sur sa vie. En effet, le récit de soi de Boris Cyrulnik est aussi un récit clinique et scientifique. Clinique, parce qu'il propose une anamnèse et une sémiologie du vécu ; scientifique, parce qu'il est éclairé par les données de la recherche actuelle. S'il sagit bien pour l'auteur de raconter son histoire, le clinicien chercheur et le pédagogue s'invitent dans le récit et poursuivent leurs objectifs: comprendre et expliquer. Comprendre et expliquer le fonctionnement de la mémoire, l'effraction traumatique et les formes de son devenir. Ainsi, Boris Cyrulnik écrit à la première personne un ouvrage sur la résilience. Les Je du narrateur autorisent des espaces de lecture différents pour lecteur. En relatant les étapes de son parcours, l'auteur insiste sur l'importance de la fictionnalisation des processus mémoriels. Se souvenir, c'est reconstruire, inventer déjà un récit qui permet d'affronter la réalité sans se disloquer : "La vérité narrative n'est pas la mémoire historique », écrit-il (p. 154). Cette vérité narrative se structure autour du feuilletage polysémique des données perceptives pour chaque individu. Le récit de soi est toujours une fiction, un roman mémoriel et non un procès-verbal comme on le souhaiterait parfois. Il se construit à partir de fragments sans cesse recomposés selon les besoins internes du sujet et de ceux de l'environnement. Cette prééminence du récit de soi entremêlé aux « récits d'alentour » est en effet essentielle pour comprendre la résilience qui ne peut s'instaurer qu'avec les autres.

Boris Cyrulnik rappelle qu'il n'existe pas d'échelle prédéterminée du malheur, mais un ensemble complexe de facteurs de risque et de facteurs de protection, inhibant ou facilitant la reprise du développement après l'effraction traumatique. Chaque individu vit donc l'évènement en fonction de ses caractéristiques personnelles dans un contexte donné. L'environnement joue effectivement un rôle crucial, tant au moment même de l'expérience que dans l'après-coup. Si, ainsi que l'a montré la psychologue

(2) « Je me suis longtemps demandé pourquoi j’ai moins souffert pendant la guerre que pendant la paix ? », Ibid., p. 169. 
Nathalie Zajde, dans son étude sur les enfants cachés ${ }^{3}$, Boris Cyrulnik a lui aussi été contraint de cliver son moi pour survivre, il met pour sa part l'accent sur les éléments et les personnes l'ayant soutenu. Ainsi, alors qu'il séjourne dans une institution maussade, l'observation attentive de l'activité des fourmis le sauve du désespoir et l'aide à entamer sa «formation de poseur de questions » (p. 89). Sont évoqués aussi tous ceux qui l'ont accompagné au fil des années : Margot, sa tante Dora, Émile, le résistant admiré, M. Mousel, le professeur de français, sorte de jumeau du M. Germain d'Albert Camus, les camarades de jeu. Lauteur rend un hommage sensible à ces aidants, car, on le comprend aisément, sans la prévoyance de sa mère, la sollicitude de Margot, la complicité de l'infirmière, la bienveillance de M. Mousel, sans la chaîne de ces personnes solidaires, pas de sauvetage possible, pas d'appui pour grandir.

Mais l'ouvrage donne aussi une place aux nombreux blessés auxquels l'auteur a consacré ses recherches: enfants et adultes maltraités, fracassés par les guerres ou brisés par la maladie ou la pauvreté. Il s'agit pour l'auteur de questionner les circonstances d'apparition de ces phénomènes, d'étudier les dispositifs d'accompagnement et de soins, d'élaborer des modes de prévention. En partageant avec le lecteur, ses interrogations et réflexions, le narrateur de ces mémoires nous apprend que la connaissance - chercher des explications - est aussi un formidable facteur de protection permettant de donner un sens partageable après la sidération de l'effroi, réinstallant de ce fait le blessé au sein de la communauté humaine dont la violence dirigée contre lui l'a exclu. Ce désir de connaissance est pluriel, allant de l'introspection à l'étude minutieuse des événements à travers de nombreux champs disciplinaires. Les surprises sont au rendez-vous et l'on peut lire dans la même page : « Tiens ! Je n’ai pas osé écrire mon arrestation, ma traque. C'est tellement plus facile de parler de soi à la troisième personne, ça tient l'évènement à distance » constate l'auteur avec amusement en convoquant dans la même chaîne associative Proust et D.L. Chacter, un chercheur en neurosciences. L'exemple illustre bien le tissage auquel se livre Cyrulnik qui ne manque pas de citer à ses côtés ses frères d'infortune, Georges Perec, Topor, Saül Friedlander et bien d'autres (p. 167).

Il fait aussi la part belle à la littérature, car écrit-il, « c'est la fiction qui a apprivoisé nos consciences et nous a aidés à envisager l'impensable » (p. 166), à affronter l'effraction de l'intentionnalité génocidaire. Dans cet espace intermédiaire, « entre le rêve et la douleur ${ }^{4} »$, la fabrique des récits insuffle la vie, envers et contre tout, malgré les difficultés à se faire entendre. Après quarante ans de silence, l'orphelin à la «parole gelée » (p. 261) par la surdité des autres parle à cœur ouvert. Il semble par moments s'en étonner, comme le révèlent, justement, ces phrases orphelines : « Facile » (p. 81), «Enfin, on en parlait!» (p. 284) par exemple ou certaines adresses au lecteur : «Ouf! J'ai eu peur que vous ne me croyiez pas » (p. 124). Ne pas le croire. Pourquoi ? Parce que sans doute, nous peinons parfois à accepter l'infinie complexité de la vie, préférant la quiétude d'une vision rassurante d'un monde en noir et blanc, manichéen, où le bonheur et le malheur sont clairement délimités.

(3) Nathalie Zajde, Les Enfants cachés en France, Paris, Odile Jacob ,2012.

(4) Jean-Bertrand Pontalis, Entre le Rêve et la douleur, Paris, Gallimard, 1977. 


\section{LIBRAIRIE}

Or, ici, comme il le faisait déjà enfant confronté à un auditoire incrédule, Cyrulnik, nous raconte de belles histoires, tout à fait incroyables : «[...] j'aurais pu expliquer qu'en plein malheur de la guerre j’avais connu des moments heureux », écrit-il (p. 85). Cette aptitude au bonheur irrigue le récit toujours animé du désir lancinant de comprendre, sous-tendu par une profonde empathie. « Ni haine ni pardon », affirme l'auteur (p. 284), mais une profonde empathie qui est aussi destinée à ceux qui font souffrir. Empathie pour le milicien battu à la libération, désir de comprendre ceux qui cèdent aux sirènes du nazisme ou du racisme, car, « haïr, c'est demeurer prisonnier du passé. Pour s'en sortir, il vaut mieux comprendre que pardonner » (p. 286). Comprendre par exemple cette scène gravée dans la mémoire : dans la synagogue où sont entassés ceux qui sont promis à la mort, un soldat en uniforme noir montre au petit garçon de 6 ans une photo de son fils auquel il ressemble. Le mémorialiste s’interroge : « Pour ne pas vivre dans la peur, avais-je besoin de penser qu'il y a des traces d'humanité même chez les persécuteurs? » (p. 26) Serait-ce décidément une histoire trop belle, une exception? Non, on retrouve une scène semblable dans le récit de Jacques Aron, enfant caché en Belgique, dont la mère a péri à Auschwitz : « Je ne me souviens pas d'avoir eu peur, ni lors de l'arrestation, ni lors de notre incarcération [...] un soldat qui nous surveillait me fit comprendre que je ressemblais à son fils, dont il me montra la photo $^{5}$. » Les deux scènes montrent l'humain sous l'uniforme annonciateur de mort.

De belles scènes? Non, elles dessinent un rêve, disent qu'il faudrait aider les humains à devenir et à rester humains, soigner les êtres brisés. Boris Cyrulnik, le petit orphelin qui s'est sauvé par une fenêtre a fait de ce projet sa vie pour affirmer qu'on peut guérir de l'effroi, se retourner sur son passé sans y périr, qu'un Juste est là quelque part, qu'ailleurs, avec les autres, dans la patience du lien, comme l'écrit Paul Eluard:

La nuit n'est jamais complète

Il y a toujours [...]

Au bout du chagrin une fenêtre ouverte

Une fenêtre éclairée

[...]Une main tendue une main ouverte

Des yeux attentifs

Une vie la vie à se partager 6 .

Une vie pour nous sauver.

(5) Jacques Aron, (1997), L'Année du souvenir. La famille, la judéité, le communisme, l'architecture, la peinture, la mort, et quelques sujets de moindre importance, Bruxelles, Didier Devillez, 2009.

(6) Paul Eluard, « Et un Sourire », in « Le Phénix. Derniers poèmes d'amour », (1951), Paris, Seghers, 1989. p. 193. 


\title{
C'étaient des enfants. Déportation et sauvetage des enfants juifs à Paris
}

\author{
Sous la direction de Sarah Gensburger, Paris, Skira/Flammarion \\ (Coll. Les expositions de l'Hôtel de Ville de Paris), 2012, 125 p.
}

\section{Le Sauvetage des enfants juifs par l'OSE}

\author{
Georges Garel, avec la participation de Katy Hazan, Paris, Le Manuscrit/ \\ Fondation pour la Mémoire de la Shoah (Coll. « Témoignages de la Shoah »), 2012, 347 p.
}

\section{Par Dina Catenaro-Catenaro, Université de Bologne}

Le catalogue C'étaient des Enfants. Déportation et sauvetage des enfants juifs à Paris, réalisé à l'occasion de l'exposition présentée à l'Hôtel de Ville à Paris du 26 juin au 27 octobre 2012, semble répondre à la nécessité de rendre justice à tous les enfants juifs parisiens victimes de la Shoah. Comme l'a affirmé le Président François Hollande à l'occasion de la cérémonie de Commémoration du soixante-dixième anniversaire de la rafle du Vélodrome d'Hiver au cours de laquelle près de 4115 enfants juifs ont été arrêtés par la police française, on ne doit pas oublier que ce crime atroce « fut commis en France, par la Francel. »

Le travail de Sarah Gensburger a une importance capitale : la reconstruction du passé par le biais d'images, de photos, de documents, de cahiers et de dessins permet au lecteur de suivre au fil des pages le sort destiné à des milliers d'enfants juifs déportés ou « rescapés » qui parvinrent à survivre grâce à l'action d'associations et d'organisations laïques et religieuses et, dans de nombreux cas, à celle de citoyens français qui décidèrent de ne pas se plier aux dictats des lois raciales.

Après une reconstruction de la composition de la population juive parisienne (une communauté hétérogène, dont les origines et les conditions sociales et économiques sont parfois très différentes), l'auteur montre le processus d'identification et d'exclusion que subirent les enfants juifs : c'est le cas de milliers d'enfants nés en France et qui sont légalement des Français, « en vertu d'une disposition de la loi républicaine de 1927 sur la naturalisation » (p. 18). À partir du statut d'octobre 1940, l'opération de stigmatisation des Juifs se concrétisa sous plusieurs formes : contrôle ainsi que fichage des adultes et des enfants et, avec l'ordonnance allemande du 28 mai 1942, imposition de l'étoile jaune. C'est à partir de ce moment-là que des réseaux d'assistance commencèrent à

(1) François Hollande, Discours du Président de la République pour le $70^{\circ}$ anniversaire de la rafle du Vel'd'Hiv', http://www.elysee.fr/president/les-actualites/discours/2012/discours-du-president-de-la-republique-pourle.13674.html 


\section{LIBRAIRIE}

se mobiliser afin de donner une aide concrète aux familles juives, en réservant une attention particulière aux enfants : parmi ces associations il y a le "Comité Amelot », l'«OSE » (Euvre de secours aux enfants) et la « Maison Verte» qui accueillirent dans leurs structures un grand nombre d'enfants juifs.

La rafle du « Vél d'Hiv » à Paris est la première concernant les enfants, une opération menée entièrement par la police française les 16 et 17 juillet 1942 : après plusieurs jours de souffrances physiques et psychologiques, les petits Parisiens sont transférés dans les camps de Loiret et de Beaune-la-Rolande, puis à Drancy, avant d'être déportés à Auschwitz. Comme l'explique bien l'auteur, l'été 1942 marque un tournant dans la persécution de la population juive : les enfants sont considérés comme des adultes et sont condamnés à mort de façon systématique dans les camps d'extermination. Toutes les œuvres sociales juives, avec le soutien de plusieurs Parisiens, ressentent alors la nécessité urgente de s'activer pour le sauvetage des enfants échappés miraculeusement à la mort : c'est le cas des « enfants cachés » qui réussirent à survivre grâce à des opérations d'assistance et de sauvetage effectuées très souvent dans la clandestinité, opérations menées non seulement par des réseaux organisés, mais aussi par de simples citoyens qui décidèrent de s'opposer à la folie du nazisme. Sarah Gensburger reconstruit minutieusement une expérience de sauvetage complexe : comme l'affirme l'auteur, « il est généralement estimé que 10000 de ces 59000 enfants juifs sont restés vivants du fait de leur prise en charge par des réseaux juifs de sauvetage, épaulés par des non-juifs. Il est toutefois difficile de fournir un chiffre définitif » (p. 101). On peut cependant affirmer que la survie de plus de $80 \%$ des enfants juifs parisiens n'aurait pas été possible sans l'aide des femmes et des hommes qui décidèrent de se mettre au service de l'humanité, en sacrifiant dans beaucoup de cas leur vie.

Parmi les associations de sauvetage, l'CEuvre de secours aux enfants (OSE), née en Russie en 1912, joue un rôle de grande importance. Les mémoires de Georges Garel, un esprit éclairé qui décida de consacrer sa vie à l'aide des enfants juifs persécutés pendant la Seconde Guerre mondiale, mettent en lumière de façon précise l'action menée par l'OSE en France, une activité qui, comme dit Garel dans l'introduction, « ne peut être dissociée ni de son temps ni de son milieu» (p. 53). C'est dans cette perspective que l'auteur parcourt l'histoire du réseau français de l'OSE, en soulignant l'importance de son activité officielle et clandestine dans un pays partagé en deux : Garel décrit les modalités d'action de l'OSE dans le nord et dans le sud de la France lors de trois périodes différentes (de juin 1940 à août 1942, d'août 1942 à février 1944, de février 1944 à la Libération) qui marquent une évolution dans le travail d'assistance menée par l'OSE, poussée à s’adapter chaque fois à de nouvelles conditions politiques, économiques et sociales.

Grâce aux mémoires de Garel et aux précieuses annotations historiques de Katy Hazan, le lecteur peut ainsi découvrir la complexité de l'action clandestine que cette association a mise en place au fil des ans comme lassistance médico-sociale dans les camps d'internement, l'accueil des enfants dans les homes, la recherche d'un travail dans les pays d'outre-mer pour les médecins juifs, les passages clandestins des enfants 
à l'étranger. Derrière chaque action de sauvetage, il y a un grand nombre de personnes qui ont sacrifié leur vie même: c'est le cas, entre autres, de Marcel Geismar, comptable au Masgelier et déporté en mai 1944, de Moïse Blumenstock, médecin fusillé en mai 1944, de Gertrude Blumenstock-Lévy, éducatrice au Masgelier assassinée en juin 1944, de Renée Gaudefroy, infirmière fusillée fin juin 1944. Comme l'affirme l'auteur dans ses mémoires, « le souvenir de leur sacrifice commandait aux survivants de remplir jusqu'au bout la mission commune. Parmi les enfants mis à l'abri par l'OSE, près de 2000 étaient désormais orphelins; parmi les enfants secourus en famille, rares étaient ceux qui avaient conservé leurs deux parents » (p. 180).

Dès la Libération, l'OSE a continué sa mission de secours aux enfants « cachés »: des enfants qui, encore aujourd'hui, éprouvent des sentiments de culpabilité envers tous ceux qui ont disparu. Dans les dernières pages de C'étaient des enfants. Déportation et sauvetage des enfants juifs à Paris, Sarah Gensburger affirme quà la fin des années 1970 les enfants juifs prennent la parole timidement et en tant qu'orphelins : « il faut attendre encore dix ans pour que ces mêmes individus s'expriment non plus seulement comme fils ou fille de, mais en quelque sorte pour eux-mêmes » (p. 121). C'est la question de l'identité qui est en jeu : la vie de ces enfants se situe entre le traumatisme du passé et son élaboration dans le présent, un équilibre difficile à atteindre, mais de toute façon nécessaire pour faire face à l'avenir.

Les deux textes semblent ainsi répondre à une double urgence : d'un côté, ils permettent au lecteur de connaître l'histoire souterraine des réseaux de résistance juive qui n’apparait pas dans les manuels d'histoire, de l'autre ils ont le mérite de donner la parole aux expériences individuelles et complexes des enfants juifs qui, trop souvent, sont cachées derrière les pièges d'une commémoration stérile dénuée de sens.

\title{
Intellectuels et artistes sous l'occupation. Et la fête continue
}

\author{
Alan Riding, Paris, Flammarion (Coll. Champs Histoire), 2013, 440 p.
}

Par Anne Roche, Université Aix-Marseille

Après les travaux fondateurs de Robert Paxton, de Philippe Burrin et d'autres, le livre d'Alan Riding se présente comme une vue synthétique du sujet. Lauteur examine successivement le cas des éditeurs, des écrivains, de la presse, des théâtres, de la musique, du cinéma, des spectacles de chansonniers, pendant l'Occupation et à la Libération, en les confrontant à la politique des Allemands, de Vichy, et à la montée progressive des mouvements de résistance. Or, nombre d'acteurs de la vie culturelle, juifs ou antifascistes connus, ont dû s'exiler ou se cacher, quand ils ne sont pas déportés, tués ou suicidés. En leur absence, qu'en est-il de la vie culturelle des autres? 
Lauteur a voulu présenter en premier lieu la richesse culturelle française dans l'entre-deux-guerres, dans les domaines de la peinture, de la musique, de la danse, de la littérature... En une trentaine de pages, cela tient de la gageure : ce chapitre n'apprendra rien au lecteur qui connaît la question, mais n'aidera pas vraiment le lecteur qui voudrait s'informer. Il en va de même des chapitres historiques, comme celui consacré à la première phase de la guerre ( Pas si drôle ») ou à sa dernière phase (« Retour de balancier »), à Vichy (« Maréchal, nous voilà!») : tout ce qui concerne la conduite de la guerre, la politique, les relations internationales, est superficiel. Il était certes utile de vouloir donner le contexte historique de la création culturelle, mais difficile de le faire si rapidement.

En revanche, les chapitres centrés précisément sur la période dans ses aspects culturels sont plus intéressants. Riding montre bien que tous les acteurs culturels sont pris dans un dilemme : beaucoup pensent que les institutions culturelles doivent continuer à fonctionner, mais leurs motivations varient. Pour ceux qui sont acquis d'emblée à la cause de la collaboration, il s'agit de coopérer avec les occupants, y compris en les divertissant: Goebbels n'a-t-il pas donné « des directives très claires pour que les Français ne produisent que des films légers, vides, et si possible stupides? » (Goebbels en 1942, cité p. 34). Pour d'autres, sans qu'ils soient déjà résistants, il ne faut pas céder à la volonté nazie d'éradiquer la suprématie de la culture française, mais tenter de la maintenir.

C'est le cas des musées dont certains rouvrent dès septembre 1940, et dont certains administrateurs tenteront courageusement de s'opposer au pillage des ouvres d'art par les nazis, alors que Vichy nélevait pas d'objections. Lauteur rappelle le courage de Rose Valland qui réussit, en demeurant à son poste au musée du Jeu de Paume, à tenir clandestinement registre de toutes les œuvres d'art qui entrent et surtout sortent, ce qui permettra après-guerre d'en retrouver parfois les propriétaires et de les restituer.

Du côté des éditeurs, on connaît les plus compromis (Grasset, Denoël) mais Riding rappelle aussi les louvoiements de Gallimard et de la NRF. Ainsi le prestigieux éditeur démet Jacques Schiffrin de ses fonctions d'éditeur de la Bibliothèque de la Pléiade, sans lui avouer que c'est parce qu'il est Juif : et André Schiffrin précise dans son livre de souvenirs ${ }^{1}$ que, ses parents étant dans une quasi-misère à New York, Gaston Gallimard ne leur envoya pas les droits afférents à la Pléiade.

Pour le cinéma, l'occupation allemande aurait-elle été un «âge d'or »? Quantitativement sans doute, puisque plus de deux cents films sont tournés en France entre 1940 et 1944, les films anglais puis américains étant interdits ainsi que les films français tournés avant 1937. Mais peu sont mémorables. La postérité a retenu Les Visiteurs du soir, qui passe pour une allégorie de la Résistance, et Le Corbeau qui en revanche vaudra à Clouzot, après la Libération, deux ans d'interdiction de tournage. Le théâtre aussi connaît une période faste, mais à la différence du cinéma, presque tous les grands du théâtre (écrivains, metteurs en scène, acteurs) restent en France.

(1) André Schiffrin, A Political Education, New York, Melville House, 2007, traduit de l'anglais (États-Unis) par Fanchita Gonzalez-Batlle sous le titre Allers-retours, Paris, Liana Lévi, 2007. 
La Reine morte, Antigone, Les Mouches, Huis clos, Le Malentendu témoignent de l'époque sous le masque du passé ou du mythe, non sans ambiguïtés : l'auteur est sévère pour Sartre et sa posture de Résistant qu'il juge usurpée.

Le rôle des écrivains est plus crucial que celui des autres artistes, dans la mesure où ils peuvent davantage représenter ce qui advient, prendre parti et influencer l'opinion. Pour la plupart, ils choisissent de continuer à publier, à quelques exceptions près. Encore faut-il distinguer entre publier des livres et collaborer à des revues ou journaux : lors de l'épuration, c'est ce dernier acte de collaboration qui sera le plus sévèrement sanctionné. « Les collaborateurs n'étaient pas si rares, mais les meilleurs écrivains français n'en faisaient pas partie » : Bernanos, Benjamin Péret, Romains, Saint-Exupéry, Gide, Martin du Gard, Mauriac, Malraux sont émigrés ou en retrait. Paulhan, Aragon, Vercors, Cassou, Char, sont activement engagés dans la Résistance.

Contrairement au légendaire gaullien qui se met en place dès $1944^{2}$, l'auteur rappelle que la Résistance a d'abord été le fait de petits groupes peu coordonnés entre eux : il consacre un chapitre émouvant au réseau dit du Musée de l'Homme ( $L a$ Résistance comme idée). Il souligne également les contradictions mineures qui se font jour entre Vichy et les Allemands : ainsi Vichy, pour contrer la supériorité affirmée de la musique allemande, passe commande à une soixantaine de compositeurs, y compris ceux du «Front national de la musique » qui regroupait les Résistants.

Le chapitre consacré à l'épuration, Vengeance et amnésie, met bien en lumière le caractère en partie « irrationnel » de cette épuration. Il rappelle en détail les procès des hommes politiques, puis ceux des écrivains et artistes, d'autant plus complexes que, dans le monde de la culture, chaque discipline a instauré ses propres comités d'épuration : pas moins de six pour les écrivains. La sévérité de la répression tient aussi au fait qu'ainsi les écrivains résistants « mettaient en évidence leur propre rôle et renforçaient leur statut social. » Après les condamnations à mort, dont peu au final sont exécutées, les emprisonnements, les interdictions de publications pour un an ou plus, les choses se calment peu à peu, grâce à la « prise de conscience qu'écrivains et journalistes étaient traités bien plus sévèrement que, par exemple, les industriels qui avaient profité de faire des affaires avec les nazis. » Dans d'autres domaines, l'épuration est moins drastique. Certains artistes sont sanctionnés par l'interdiction d'exposer ou de vendre, mais pas les galeries, y compris celles qui avaient vendu des œuvres volées à des Juifs : « une fois de plus, les artistes étaient soumis à des exigences morales plus élevées que les hommes d'affaires. »

L'auteur pour finir se demande si Paris a perdu sa place de cœur de la création, et note qu’à partir de la guerre les arts visuels sont centrés à New York. Sur les intellectuels, on hésitera davantage à le suivre quand il écrit : « Aucun autre pays probablement n'illustre mieux les périls auxquels s'expose un peuple habitué à révérer les théories : il devient un terrain fertile pour l'extrémisme. [...] Si les intellectuels français n'ont plus la même autorité qu'autrefois, c'est parce que leurs doctrines ont échoué et que

(2) Cf. Pierre Laborie, Le Chagrin et le venin. La France sous l'occupation, mémoire et idées reçues, Paris, Bayard, 2011. 


\title{
LIBRAIRIE
}

les mirages de l'Utopie ont disparu. » Enfin, à la question de savoir si la période de l'Occupation a été un « âge d'or » sur le plan culturel ou une période de stérilité et de désespoir, l'auteur cherche à apporter une réponse nuancée, mais il écrit tout de même: « [Les Allemands] chassèrent et persécutèrent les artistes juifs mais donnèrent ainsi plus de place à de nouveaux talents en France.» On veut croire que cela lui a échappé.

\section{Histoire des Justes en France}

\author{
Patrick Cabanel, Paris, Armand Colin, 2012, 414p.
}

Par Léon Strauss, Université de Strasbourg

Les trois quarts des Juifs résidant en France de 1940 à 1944 ont survécu au Grand Massacre des Juifs d'Europe. Cette survie est le produit de facteurs multiples, dont le plus important est sans doute la Libération qui mit fin, durant l'été 1944 sur la majeure partie du territoire, au sinistre travail de la Police allemande et de la Milice assistées trop souvent par la Police et la Gendarmerie françaises. Il n'en demeure pas moins que depuis juin 1940, des milliers de Français ou d'étrangers non-juifs résidant en France avaient entrepris d'aider et de sauver les Juifs français et étrangers en butte aux persécutions et, depuis 1942, à la déportation dans les camps de la mort. Ces sauveteurs furent peu reconnus et honorés dans les années qui suivirent la guerre. C'est le nouvel État d'Israël qui, en 1953, dans la loi créant le Mémorial de Yad Vashem, reprit une expression rabbinique médiévale pour commémorer les « Justes parmi les nations qui ont risqué leur vie pour venir en aide aux Juifs. » Depuis 1963, une commission israélienne attribue le titre de « Juste parmi les Nations » au vu d'un dossier produit par les Juifs sauvés. Les premiers Justes français furent désignés en 1964. En mars 2013, on en comptait 3 728, selon le comité français de Yad Vashem. La liste va se clore dans une dizaine d'années quand le dernier rescapé susceptible de témoigner aura disparu.

Patrick Cabanel, professeur d'histoire contemporaine à l'université de Toulouse - Le Mirail, avait déjà enrichi la bibliographie sur les Justes de France en participant à la publication de l'enquête des années 1980 sur les Cévennes, terre de refuge et en publiant en 2010 un très beau livre sur Alice Ferrières, professeur à Murat (Cantal), la première Française nommée Juste en 1964. Avec ce nouvel ouvrage, il nous procure une véritable synthèse scientifique sur le sauvetage des Juifs en France. Qu'il soit bien entendu que cette appréciation n'entend nullement effacer les grands mérites des publications pionnières, comme celles de Lucien Lazare, Israël Gutman, Limore Yagil.

Le premier chapitre montre comment la mémoire du sauvetage des Juifs s'est construite en France. Alors qu'Israël ne commença réellement cette commémoration qu’à la suite du procès Eichmann (1961), dès la Libération, les organisations protestantes publièrent des bilans de leurs activités de résistance et d'aide aux Juifs. En 1947, des 
organisations juives rendirent hommage aux « nobles figures du peuple français qui ont bravé tous les dangers pour sauver des enfants juifs de la déportation. » Quelques sauveteurs furent honorés par la République qui leur décerna des médailles de la Résistance ou de la Reconnaissance française ; certains personnages collectifs (Le Chambon, la Cimade) furent très tôt mis en exergue. Si à partir de 1962, quelques dizaines de sauveteurs de France furent nommés « Justes », il fallut attendre 1988 pour que se produise une accélération importante de leurs effectifs alors que les Justes néerlandais et polonais étaient déjà nombreux dès les années 1960. La gloire montante du Chambon-sur-Lignon, le succès du film de Louis Malle, « Au revoir les enfants », plusieurs discours ou initiatives du président Chirac ont mis la Shoah et le Sauvetage au premier plan de la Mémoire nationale de la Seconde Guerre mondiale. Du coup, se réveillèrent les souvenirs de nombreux rescapés encore vivants qui prirent l'initiative de retrouver leurs sauveurs ou leurs descendants et entreprirent la démarche.

Lauteur passe ensuite à une analyse méthodique de la population en cause : les Justes français. Il rappelle d'abord et le discours de la psychologie sociale anglosaxonne sur la personnalité altruiste, et celui du « Livre des Justes » de Lucien Lazare qui se refusait à dépasser la collection de biographies d'individus héroïques et estimait que toute analyse d'ordre sociologique ou analytique était vouée à l'échec. Ces deux approches ont conduit à sous-estimer le caractère collectif d'une bonne partie du sauvetage des Juifs. Une troisième voie est possible : on peut ébaucher une sociologie et une géographie des Justes. Fort précisément, Cabanel rappelle à ce moment que l'histoire des Justes n'épuise pas celle du sauvetage des Juifs. Yad Vashem n'a pas toujours retenu des proches des Justes en dépit de leurs titres à le devenir (etj’ajouterai que plus nombreux encore sont ceux qui ne lui ont jamais été signalés, car personne n’a jamais pu - ne serait-ce parce que les survivants ignoraient tout de l'identité de leurs sauveteurs - ou voulu témoigner de leurs services). Et puis, le sauvetage des Juifs a d'abord été le sauvetage des Juifs par eux-mêmes, qu'ils aient agi à titre individuel ou aient milité dans des associations ou réseaux juifs.

La majeure partie de l'ouvrage est consacrée à une étude historique des Justes qui essaie d'identifier des figures collectives géographiques, professionnelles, confessionnelles. Pour la période qui va de l'armistice de juin 1940 à l'invasion allemande de la zone libre en novembre 1942 sont cités les premiers Justes : les diplomates étrangers qui risquèrent et brisèrent leur carrière pour distribuer des visas aux candidats à l'émigration, le groupe de sauveteurs tchèques, Varian Fry, le célèbre Américain de Marseille, les groupes protestants et catholiques agissant dans les camps d'internement où croupissaient de nombreux Juifs étrangers et qui se retrouvaient dans le comité de coordination pour l'assistance dans les camps, dit Comité de Nîmes avec les organisations juives et la Croix Rouge. Les rafles d’août 1942 dans les camps de la zone non occupée conduisirent ces œuvres à sortir de la légalité pour tenter de sauver le plus possible de ces malheureux que Vichy voulait livrer aux Nazis, en particulier des enfants qu'il fallut séparer de leurs parents, et puis, de hauts serviteurs de l'État comme le gouverneur militaire de Lyon, le commandant du camp des Milles refusèrent de participer à l'opération et acceptèrent donc pour l'un 


\section{LIBRAIRIE}

d'être mis à la retraite ou pour l'autre d'être emprisonné. Pour la première fois, depuis l'établissement du régime autoritaire, des voix éminentes émirent des protestations publiques largement diffusées malgré la censure: Mgr Saliège, Mgr Théas, Mgr Gerlier, Mgr Moussaron, le pasteur Boegner.

Le sauvetage peut être cartographié. Au premier plan, ces terres de refuge huguenotes que furent le plateau du Chambon-sur-Lignon, le massif des Cévennes, les campagnes protestantes des Deux-Sèvres, ce village de Justes que fut Dieulefit. Mais le livre met aussi en valeur des « poches de refuge » catholiques comme Moissac et d'innombrables localités et institutions comme l'école primaire supérieure de Murat ou l'école normale d'instituteurs du Bas-Rhin repliée à Solignac. Il faut aussi évoquer les zones frontières (extérieures, mais aussi intérieures), celles qu'il faut franchir le plus vite possible pour passer clandestinement hors du territoire contrôlé par l'Occupant. Là aussi, que ce soit pour franchir la ligne de démarcation entre zone Nord et zone Sud ou la frontière suisse (en espérant qu'on ne soit pas refoulé par la police peu accueillante de ce pays neutre) ou espagnole, rien n'était possible sans de précieux auxiliaires, convoyeurs et passeurs juifs, mais aussi dans les mêmes fonctions bénévoles nombreux frontaliers, comme les 39 Justes de Haute-Savoie repérés par Cabanel. La vocation de l'ouvrage ne permet pas de parler des filières payantes qui fleurirent jusqu'en 1943. Ces profiteurs du malheur sont évoqués dans le livre d'Éric Alary sur la ligne de démarcation.

Le dernier chapitre est consacré aux Justes qui ont sauvé des enfants et qui ont largement contribué à ce que $86 \%$ des enfants juifs de France aient survécu à l'Extermination. Le rôle des organisations juives, notamment l'OSE du docteur Joseph Weill et d'Andrée Salomon et les Éclaireurs israélites de France, fut très important à cet égard. Mais il fallait trouver des familles ou des hébergements collectifs pour ces « enfants cachés » : des milliers de familles les ont accueillis, gratuitement ou moyennant le payement d'une pension. D'autres purent continuer leur scolarité, sous de fausses identités, grâce aux internats de l'enseignement privé ou de l'enseignement public qui les accueillirent en toute connaissance de cause. Lauteur n'hésite pas à traiter la délicate question des baptêmes catholiques ou protestants, qui conduisit après guerre à des drames, comme l'affaire Finaly. Mais il cite aussi de nombreux contre-exemples : le pasteur qui ouvre son temple à l'office juif de Pourim, la famille protestante qui fait réciter leur prière juive aux deux fillettes accueillies tous les soirs, les chefs d'établissements catholiques qui inscrivent les élèves juifs comme protestants pour pouvoir les dispenser de participation aux offices religieux. Il sait aussi signifier que le sauvetage ne vint pas seulement d'une portion significative des milieux confessionnels protestants (qu'il connaît particulièrement) ou catholiques, mais que s'engagèrent aussi dans cette « Résistance civile » de nombreux militants de la laïcité ou des communistes et toutes sortes de personnes de bonne volonté.

Ce compte-rendu est loin d'épuiser la richesse de cet ouvrage qui réussit à combiner les exemples concrets d'actions d'individus ou de groupes sans verser dans l'anecdotique et l'analyse plus distanciée de phénomènes collectifs. On regrettera seulement le parti pris initial de se limiter au corpus des Justes homologués par Yad 
Vashem d'autant plus que, très souvent, l'auteur cite d'autres sauveteurs en se croyant obligé de préciser qu'ils ne sont pas Justes. Le formalisme juridique qui impose des témoignages de survivants prive ainsi du titre une personnalité aussi incontestable que Mgr Bruno de Solages. Et, Patrick Cabanel reconnaît d'ailleurs que les enfants cachés ignoraient souvent le nom de leurs sauveteurs. Je peux témoigner moi-même de cette difficulté puisque je suis toujours incapable de me remémorer qui mavait remis à Clermont-Ferrand vers mai 1944 (javais pourtant 16 ans) de fausses cartes d'identité pour ma famille, dont celle qui a permis à mon père d'échapper à l'arrestation par des auxiliaires français de la Gestapo en juin 1944.

\section{L'Église de France face à la persécution des Juifs, 1940-1944}

\section{Sylvie Bernay, Paris, CNRS éditions, 2012, 527 p.}

Par Gilles Ferragu, ISP - Université Paris Ouest Nanterre

De l'Église catholique pendant la guerre, on garde plusieurs images : celle d'une institution accueillant avec ferveur la Révolution nationale et sa promesse de redressement moral, mais qui sait également protéger, en son sein, les auteurs des Cahiers du témoignage chrétien, défenseurs d'une France qui risquait de perdre son âme (selon la célèbre formule du père Fessard s.j.). Hors de tout jugement moral, qui n'est pas la mission de l'historien, la question des attitudes de l'Église catholique est complexe, souvent résumée à des actes individuels plutôt qu'à une démarche collective forcément simplificatrice. Car l'Église ne se résume ni à Rome, ni à l'Épiscopat, ni même à la hiérarchie ecclésiastique, et son histoire suppose donc de l'appréhender dans toute sa complexité, comme institution et comme assemblée de croyants. Cette histoire, Mme Sylvie Bernay la confronte aux préjugés, aux stéréotypes et, au crible d'un important travail dans les archives. Elle entreprend d'analyser les attitudes et les comportements religieux face à un drame dont le poids pèse encore dans les mémoires, celui des persécutions antisémites. Soulignons déjà l'ampleur des recherches effectuées, tant dans des archives publiques (Ministère des Affaires étrangères) que privées, catholiques (fonds de l'Assemblée des cardinaux et archevêques, de chancelleries diocésaines, d'institutions, de congrégations et de monastères) et juives (fonds du Consistoire central, du Centre de Documentation juive contemporaine), en France et hors de France (fonds des Justes à Yad Vashem). Un travail essentiel pour entrer dans le débat historiographique (avec les ouvrages notables de Jacques Duquesne et plus récemment de Michèle Cointet) et dégager, hors de quelques schémas particuliers déjà bien connus (les cardinaux Suhard, Tisserant, Gerlier, Baudrillard, etc.) des tendances plus générales. 


\section{LIBRAIRIE}

La démonstration débute par une réflexion qui, sans être neuve, est parfaitement appropriée, sur les rapports entre catholicisme et judaïsme dans la France d'avant guerre. Car, au-delà de la question déjà passionnante des attitudes ecclésiastiques durant la guerre, Mme Bernay s'intéresse à la problématique du dialogue interreligieux, non pas dans sa conclusion vaticane et conciliaire, mais dans ses prémices. Avec l'avènement, en 1933, du régime nazi, la question du rapport au judaïsme s'impose brutalement dans l'Europe religieuse, et l'auteur montre bien que si les débats théologiques persistent et qu'un antijudaïsme demeure, reflet d'une mentalité « préconciliaire », la politique antisémite amène une réaction, la formation d'un « front interconfessionnel » qui va du simple soutien à une aide active pour les réfugiés juifs. La promesse d'aide, faite par le cardinal Suhard (Paris) au grand rabbin, le 22 décembre 1941, témoigne de la persistance de ce front, dans le secret et la clandestinité.

Car cette position devient plus complexe avec la défaite, l'occupation et l'établissement d'un nouveau régime. Certes, le constat préalable est celui de la « divine surprise » vichyssoise proclamée par Charles Maurras. Et le cardinal Gerlier de s'exclamer : « Travail, famille, patrie : ces trois mots sont les nôtres. » Dans les faits, l'épiscopat apparaît pourtant divisé entre zone libre et zone occupée, entre espoir d'un renouveau catholique et réalité de l'occupation allemande. La doctrine de l'Église est « engagée » (p.300), mais cet engagement même incite à la prudence et la hiérarchie apparaît très divisée, notamment en zone occupée. C'est notamment autour de la politique antisémite et des statuts des Juifs que l'auteur a cherchél'indice d'une réaction de l'Église en corps, mais, hormis les démarches individuelles de certains évêques, la seule protestation effective est la déclaration du 24 juillet 1941, déclaration qui vise « discrètement, mais nettement » (Mgr Gerlier, cité p. 183) la question juive. Il est vrai qu'une partie du clergé reste attaché au principe du « double protectorat », et d'un statut spécifique pour la communauté juive, c'est alors dans les démarches individuelles, et communautaires qu'il faut rechercher une résistance plus active, celle des réseaux de sauvetage, voire des diocèses refuge (Marseille, Toulouse, Tulle, Nice, etc.). La Résistance imprime sa marque au monde catholique qui développe à son tour faux papiers et filières d'extraction, en alternant toutefois l'engagement humaniste avec le souci des âmes et des conversions - le Juif idéal demeure le Juif converti. Laumônerie catholique, les Filles de la Charité, les Pères et les Dames de Sion, le Secours national, et nombre d'institutions, jouent notamment ce rôle entre protection, dissimulation, résistance et dialogue. Autre sujet sur lequel ce travail donne lieu à une relecture, la trajectoire de Mgr Valerio Valeri, nonce auprès du gouvernement de Vichy, apparaît plus complexe, et manifeste, dans son ressort français, la politique de Pie XII (une politique bien comprise dans certains diocèses), qui préférait les discrètes interventions diplomatiques à une réprobation plus médiatique et plus risquée. Ses interventions en faveur de la communauté juive, notamment auprès de l'occupant italien, furent souvent couronnées de succès et méritent d'être citées.

Tiré d'une thèse de doctorat d'histoire contemporaine, soutenue en Sorbonne en 2010, cet ouvrage de qualité en a toutes les exigences : un appareil de notes qui inclut la bibliographie, un index des noms de personne, un catalogue d'archives important. De 
la sorte, il constitue un instrument scientifique de qualité, désormais indispensable aux travaux sur l'histoire de l'Église de France dans la guerre mondiale. Certes, le tableau esquissé ici est celui d'une Église résistante et compatissante - les prélats les plus engagés dans la collaboration et la politique antisémite ont été discrètement écartés du corpus - mais tel quel, ce travail riche, précis, novateur (notamment quant à la politique menée par Mgr Valeri) offre une vue d'ensemble de ce que fut la politique d'entraide et de sauvetage et, au-delà, la mise en place d'un dialogue qui aboutit à la déclaration Nostra Aetate (1965). 